\title{
Nebulised fenoterol compared with metered aerosol
}

\author{
C MELVILlE, P D PHELAN, AND L I LANDAU \\ Professorial Department of Thoracic Medicine, Royal Children's Hospital, Melbourne, Australia
}

SUMMARY The effect of nebulised fenoterol was compared with that of a similar dose administered by metered aerosol in 14 children, aged 7 to 17 years with moderately severe asthma. The initial response to fenoterol delivered by metered aerosol or nebuliser was the same, but a second dose by nebuliser after a dose by metered aerosol produced maximum potential bronchodilatation which was not seen when a second dose by metered aerosol was given after that by nebuliser. Administration of a bronchodilator by nebuliser does seem advantageous in the treatment of some children.

Inhaled sympathomimetic agents are effective bronchodilators in the management and long term prophylaxis of acute asthma. There is, however, considerable difference of opinion regarding the effective dose and the best method of administration. ${ }^{1}$ Studies on the effective dose of aerosol bronchodilators are difficult to perform because of the considerable variability in the proportion of the administered dose reaching the lower airways. ${ }^{2}$ In practice, the metered aerosol is generally used for mild attacks of asthma and for long term prophylaxis. Nebulised beta agonists are reserved for severe episodes and long term management of a small group of severe chronic asthmatics. It has been proposed that the nebulised solution is more effective than the metered aerosol in those with more severe asthma. ${ }^{3}$ Reilly and colleagues ${ }^{4}$ reported that 100 to $300 \mu \mathrm{g}$ fenoterol delivered by aqueous nebulisation achieved optimal bronchodilatation with no detectable cardiovascular side effects. We compared the relative efficiency of nebulised fenoterol solution with a similar dose delivered by metered aerosol in children with moderately severe chronic asthma.

\section{Methods}

Fourteen asthmatic children, eight boys and six girls, aged 7 to 17 years were enrolled in the study. Severity of the asthma varied with forced expiratory volume in one second $\left(\mathrm{FEV}_{1}\right)$ ranging from 33 to $106 \%$ predicted. Most were moderately severe with nine of the 14 subjects having a baseline $\mathrm{FEV}_{1}$ less than $80 \%$ predicted. All sympathomimetic medica- tions were withheld for at least eight hours before the start of the study and long acting theophylline preparations were not taken for at least 12 hours. All children attended for one treatment regimen and were randomly assigned to that regimen. There were no differences in age, sex, or severity of asthma between groups. Recruitment was determined by those who were able to perform the forced expiratory manoeuvres and to use a metered aerosol effectively.

Peak expiratory flow (PEF) was measured with a Wright peak flow meter (Airmed). Forced expiratory volume in one second and forced expiratory flow in the mid vital capacity range $\left(\mathrm{FEF}_{25-75}\right)$ were measured with a nine litre water-filled Goddart expirograph. The maximum values of at least two readings which agreed within $5 \%$ were recorded.

After the baseline measurements, the subjects received one of four regimens:

(1) One puff $(200 \mu \mathrm{g})$ of metered aerosol fenoterol followed 90 minutes later by $250 \mu \mathrm{g}$ fenoterol $(0 \cdot 1 \%)$ administered as a wet aerosol. The aerosol was nebulised via a Bennett nebuliser using an air flow of 6 to 8 litres/minute. Nebulisation was continued until the reservoir was dry, usually after 10 minutes.

(2) One puff fenoterol metered aerosol $(200 \mu \mathrm{g})$ followed at 90 minutes by $500 \mu \mathrm{g}$ wet aerosol of fenoterol by nebuliser.

(3) Wet aerosol of fenoterol by nebuliser (500 $\mu \mathrm{g})$ followed at 90 minutes by $200 \mu \mathrm{g}$ fenoterol by metered aerosol.

(4) Wet aerosol of fenoterol by nebuliser ( 250 $\mu \mathrm{g}$ ) followed at 90 minutes by $200 \mu \mathrm{g}$ fenoterol by metered aerosol.

Pulmonary function measurements were made at baseline and 15, 30, 60, 90, 105, 120, 150, and 180 minutes after the first administration of fenoterol. Subjective side effects were recorded.

Results were plotted on a per cent predicted axis to show the effect of severity of asthma on the responses to either treatment regimen. ${ }^{5}$ Per cent increase in $\mathrm{FEV}_{1}$ was calculated for either technique from the two baselines at 0 and 90 minutes. Cumulative dose response was plotted for each patient by recording the per cent increase from baseline at each time during the two methods of administration over three hours. Responses to the 
Table Change in lung function indices in relation to the various aerosol administrations of fenoterol

\begin{tabular}{|c|c|c|c|}
\hline & $\begin{array}{l}\text { Mean increase in PEF } \\
(\%)\end{array}$ & $\begin{array}{l}\text { Mean increase in FEV, } \\
(\%)\end{array}$ & $\begin{array}{l}\text { Mean increase in } F E F_{25-75} \\
(\%)\end{array}$ \\
\hline \multicolumn{4}{|l|}{ Series 1} \\
\hline (a) $200 \mu \mathrm{g}$ by metered aerosol & 36 & 54 & 67 \\
\hline (b) $250 \mu \mathrm{g}$ by nebuliser & 14 & 32 & 43 \\
\hline \multicolumn{4}{|l|}{ Series 2} \\
\hline (a) $200 \mu \mathrm{g}$ by metered aerosol & 13 & 20 & 40 \\
\hline (b) $500 \mu \mathrm{g}$ by nebuliser & 12 & 19 & 50 \\
\hline \multicolumn{4}{|l|}{ Series 3} \\
\hline (a) $500 \mu \mathrm{g}$ by nebuliser & 86 & 44 & 74 \\
\hline (b) $200 \mu \mathrm{g}$ by metered aerosol & 12 & 9 & 32 \\
\hline \multicolumn{4}{|l|}{ Series 4} \\
\hline (a) $250 \mu \mathrm{g}$ by nebuliser & 75 & 36 & 77 \\
\hline (b) $200 \mu \mathrm{g}$ by metered aerosol & 5 & 10 & 37 \\
\hline
\end{tabular}

$\mathrm{PEF}=$ peak expiratory flow; $\mathrm{FEV}_{1}=$ forced expiratory volume in one second: $\mathrm{FEF}_{25-75}=$ forced expiratory flow in the mid vital capacity range.

various treatment regimens were analysed by unpaired Student's $t$ test.

The study was approved by the Ethics Committee of this institution. Parents and all the children were given a detailed explanation of the study and signed a consent form agreeing to participate in the trial.

\section{Results}

Both techniques of administration of fenoterol produced effective bronchodilatation without appreciable tremor, palpitations, or other cardiovascular side effects. The mean responses for each drug administration from baseline and 90 minutes on PEF, $\mathrm{FEV}_{1}$, and $\mathrm{FEF}_{25-75}$ are shown in the Table.

Compared with baseline, both methods of administration produced adequate bronchodilatation. The mean increase after nebulisation by $250 \mu \mathrm{g}$ or $500 \mu \mathrm{g}$ of wet aerosol fenoterol was slightly greater but not statistically significantly different from that after metered aerosol (mean increase in $\mathrm{FEV}_{1}$ after wet nebuliser was $87 \%$, mean increase after metered aerosol was $63 \%, P=0 \cdot 07$ ). There was no significant difference between the response to $250 \mu \mathrm{g}$ or $500 \mu \mathrm{g}$ of wet aerosol fenoterol by nebulisation.

The response to either $250 \mu \mathrm{g}$ or $500 \mu \mathrm{g}$ of wet aerosol fenoterol by nebulisation after previous metered aerosol dosage was significantly greater $(\mathrm{P}<\cdot 05)$ than that to $200 \mu \mathrm{g}$ of metered aerosol after previous wet aerosol by nebulisation (Figure).

There was no significant change in these observations if the group with more severe asthma and a $\mathrm{FEV}_{1}$ of less than $70 \%$ predicted normal was analysed separately.

\section{Discussion}

For mild to moderate asthma, the initial response to fenoterol by metered aerosol or wet aerosol using a

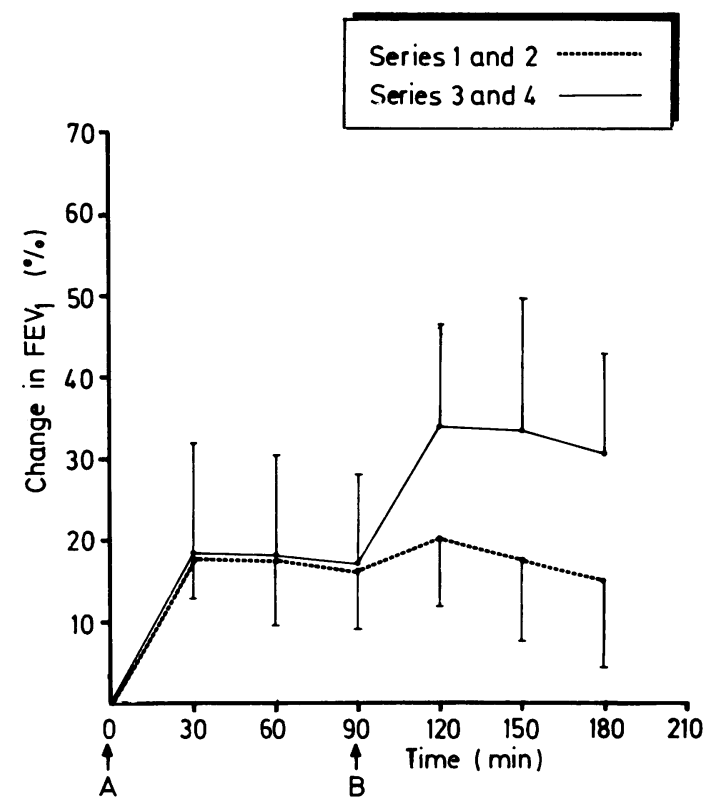

Figure Percentage change in forced expiratory volume in one second $(F E V$, from initial baseline in relation to time after administration of aerosol fenoteral at $O(A)$ and $90(B)$ minutes.

Series $1+2=$ metered acrosol at time A, nebulised acrosol at time B. Series $3+4=$ nebulised acrosol at time $A$. metered acrosol at time B. Standard deviations shown.

nebuliser was not significantly different. The dose administered by metered aerosol was $200 \mu \mathrm{g}$ and that by wet nebuliser either $250 \mu \mathrm{g}$ or $500 \mu \mathrm{g}$, there being no greater response to the higher dose of the latter.

A significantly greater response by nebuliser given 90 minutes after metered aerosol was seen but this was not apparent when given in the reverse 
order. It seems, using a cumulative dose response, that the metered aerosol after nebuliser did not allow maximum potential increase in lung function.

Previous studies comparing metered aerosol with nebuliser have used different dosages. ${ }^{3}$ This has led to argument about whether different responses were related to the dose or the method of administration. In this study, the doses were similar, although the amount reaching the lower airways cannot be clearly predicted. It is likely that only a small fraction, probably less than $20 \%$ of each dose, did reach the lower airways, but slight differences do not seem to be significant. The nebuliser technique used was such that much of the dose was wasted during the expiratory phase of ventilation. The minimal effect of dose on the response in this study of children with mild to moderate asthma agrees with the observation of Reilly et $a l^{4}$ and Ruffin et $a t^{6}$.

Tarala $e t \mathrm{al}^{7}$ showed that repeated puffs of metered dry aerosol would give a similar response to a wet aerosol, although the wet aerosol did produce significantly greater bronchodilatation after six to eight puffs of dry aerosol, supporting the observations in this study.

For most patients the choice between a metered aerosol and nebuliser for administration of sympathomimetic drugs should be based on cost, age, and ability to use a metered aerosol, as there is little difference in the response by either route. For most children with asthma over 4 to 6 years of age, a dry or metered aerosol is adequate. Wet aerosol by nebuliser does seem, however, to be more effective in achieving maximum potential bronchodilatation and is probably the treatment of choice in troublesome chronic asthma as well as during the severe acute episode when inhalation of the metered aerosol dose is difficult.

C $M$ was supported by a travelling fellowship funded by Bochringer-Ingelheim.

\section{References}

1 Anonymous. Management of severe acute asthma [Editorial]. Br Med J 1978;i:873-4.

2 Shenfield GM, Paterson JW. Clinical assessment of bronchodilator drugs delivered by acrosol. Thorax 1973;28:124-8.

${ }^{3}$ Chook-Kang YFJ, Grant IWB. Comparison of two methods of administering bronchodilator acrosol to asthmatic patients. $\mathrm{Br}$ Med J 1975;ii:119-20.

+ Reilly PA, Yahar J, Mindorff C, Kazim F, Levison H. Dose-response characteristics of nebulized fenoterol in asthmatic children. J Pediatr 1983:103:121-6.

5 Polgar G, Promadhat V. Pulmonary function testing in children. Philadelphia: Saunders, 1971.

'Ruffin RW, Montgomergy JM, Newhova MT. Site of beta adrenergic receptors in the respiratory tract: use of fenoterol administered by two methods. Chest 1978:74:256-60.

7 Tarala RA, Madsen BW, Paterson JW. Comparative efficacy of salbutamol by pressurized acrosol and wet nebulizer in acute asthma. Br J Clin Pharmacol 1980;10:393-7.

Correspondence to Professor L I Landau, Department of Child Health, Princess Margaret Hospital for Children, Box D184, GPO. Perth, Western Australia, 6001 Australia.

Received 28 September 1984

\title{
Inspiratory time and tidal volume during intermittent positive pressure ventilation
}

\author{
D FIELD, A D MILNER, AND I E HOPKIN
}

Department of Neonatal Medicine and Surgery, City Hospital, Nottingham

SUMmARY We measured the tidal volume achieved during intermittent positive pressure ventilation using various inspiratory times with a minimum of $0 \cdot 2$ seconds. Results indicate that tidal volume shows no reduction with inspiratory times down to 0.4 seconds. An inspiratory time of 0.3 seconds, however, is likely to reduce tidal volume by $8 \%$, and at $0 \cdot 2$ seconds a $22 \%$ fall may be anticipated.

For the past 10 years most babies with the idiopathic respiratory distress syndrome have been ventilated using square wave ventilation at ventilator rates ranging from 20 to 40 breaths per minute. Willingness to exceed a respiratory rate of 40 seems to be limited by a belief that short inspiratory times do not provide adequate oxygenation. ' During the past year we have found that ventilator rates of up to 100 breaths per minute may produce considerable benefit. ${ }^{2}$ We were, however, concerned that very brief inspiratory times might reduce tidal volume appreciably, which would result in alveolar hypoventilation. We therefore attempted to assess at what inspiratory time a fall in tidal volume was likely to occur. 